\title{
RESEARCH
}

Open Access

\section{Variations in accelerometry measured physical activity and sedentary time across Europe - harmonized analyses of 47,497 children and adolescents}

Jostein Steene-Johannessen ${ }^{1 *}\left(\mathbb{D}\right.$, Bjørge Herman Hansen ${ }^{1}$, Knut Eirik Dalene $^{1}$, Elin Kolle ${ }^{1}$, Kate Northstone ${ }^{2}$, Niels Christian Møller ${ }^{3}$, Anders Grøntved ${ }^{3}$, Niels Wedderkopp ${ }^{3}$, Susi Kriemler ${ }^{4}$, Angie S. Page ${ }^{5}$, Jardena J. Puder ${ }^{6}$, John J. Reilly ${ }^{7}$, Luis B. Sardinha ${ }^{8}$, Esther M. F. van Sluiijs ${ }^{9}$, Lars Bo Andersen ${ }^{10}$, Hidde van der Ploeg ${ }^{11}$, Wolfgang Ahrens ${ }^{12}$, Claudia Flexeder ${ }^{13}$, Marie Standl ${ }^{13}$, Holger Shculz $^{13}$, Luis A. Moreno ${ }^{14}$, Stefaan De Henauw ${ }^{15}$, Nathalie Michels ${ }^{15}$, Greet Cardon ${ }^{15}$, Francisco B. Ortega ${ }^{16}$, Jonatan Ruiz ${ }^{16}$, Susana Aznar ${ }^{17}$, Mikael Fogelholm ${ }^{18}$, Andrew Decelis ${ }^{19}$, Line Grønholt Olesen ${ }^{3}$, Mads Fiil Hjorth ${ }^{20}$, Rute Santos ${ }^{21}$, Susana Vale ${ }^{22}$, Lars Breum Christiansen ${ }^{3}$, Russ Jago ${ }^{5}$, Laura Basterfield ${ }^{23}$, Christopher G. Owen ${ }^{24}$, Claire M. Nightingale ${ }^{24}$, Gabriele Eiben ${ }^{25}$, Angela Polito ${ }^{26}$, Fabio Lauria ${ }^{27}$, Jeremy Vanhelst ${ }^{28}$, Charalambos Hadjigeorgiou ${ }^{29}$, Kenn Konstabel ${ }^{30}$, Dénes Molnár ${ }^{31}$, Ole Sprengeler ${ }^{12}$, Yannis Manios ${ }^{32}$, Jaanus Harro ${ }^{33}$, Anthony Kafatos ${ }^{34}$, Sigmund Alfred Anderssen ${ }^{1}$, Ulf Ekelund ${ }^{1}$ and On behalf of the Determinants of Diet and Physical Activity knowledge hub (DEDIPAC); International Children's Accelerometry Database (ICAD) Collaborators, IDEFICS Consortium and HELENA Consortium

\footnotetext{
Abstract

Background: Levels of physical activity and variation in physical activity and sedentary time by place and person in European children and adolescents are largely unknown. The objective of the study was to assess the variations in objectively measured physical activity and sedentary time in children and adolescents across Europe.

Methods: Six databases were systematically searched to identify pan-European and national data sets on physical activity and sedentary time assessed by the same accelerometer in children (2 to 9.9 years) and adolescents ( $\geq 10$ to 18 years). We harmonized individual-level data by reprocessing hip-worn raw accelerometer data files from 30 different studies conducted between 1997 and 2014, representing 47,497 individuals (2-18 years) from 18 different European countries.

Results: Overall, a maximum of $29 \%$ ( $95 \%$ Cl: 25,33$)$ of children and $29 \%(95 \%$ Cl: 25,32$)$ of adolescents were categorized as sufficiently physically active. We observed substantial country-and region-specific differences in physical activity and sedentary time, with lower physical activity levels and prevalence estimates in Southern European countries. Boys were more active and less sedentary in all age-categories. The onset of age-related lowering or leveling-off of physical activity and increase in sedentary time seems to become apparent at around 6 to 7 years of age.

(Continued on next page)
}

\footnotetext{
* Correspondence: josteinst@nih.no

${ }^{1}$ Department of Sports Medicine, Norwegian School of Sport Sciences, PO

Box 4014, Ullevål Stadion, 0806 Oslo, Norway

Full list of author information is available at the end of the article
}

(c) The Author(s). 2020 Open Access This article is distributed under the terms of the Creative Commons Attribution 4.0 International License (http://creativecommons.org/licenses/by/4.0/), which permits unrestricted use, distribution, and reproduction in any medium, provided you give appropriate credit to the original author(s) and the source, provide a link to the Creative Commons license, and indicate if changes were made. The Creative Commons Public Domain Dedication waiver (http://creativecommons.org/publicdomain/zero/1.0/) applies to the data made available in this article, unless otherwise stated. 
(Continued from previous page)

Conclusions: Two third of European children and adolescents are not sufficiently active. Our findings suggest substantial gender-, country- and region-specific differences in physical activity. These results should encourage policymakers, governments, and local and national stakeholders to take action to facilitate an increase in the physical activity levels of young people across Europe.

\section{Introduction}

There is compelling evidence that higher levels of physical activity are associated with substantial health benefits in young people [1, 2], these benefits seem to be independent of sedentary time [3]. Young people nevertheless spend a large proportion of their waking hours sedentary and many do not appear to be physically active according to the current public health recommendations [4]. Previous studies examining accelerometermeasured physical activity from a diverse range of European children and adolescents suggest a substantial variation in physical activity levels across studies [4-8]. Much of this variation, however, may be artefactual, explained by differences in the methodologies used to reduce, processing, and analyze the accelerometer data [9]. This limitation can be overcome by combining and reprocessing individual-level data from existing studies in a harmonized and standardized manner. This would provide a more consistent and comprehensive estimate of the levels of physical activity and sedentary time in European youth that could inform public-health policymakers across Europe.

The International Children's Accelerometry Database (ICAD) [9], has already developed standardized methods to create comparable physical activity variables from more than 20 studies including more than 32,000 participants. Cooper et al. [4] used this database to describe variations in physical activity and sedentary time between seven European countries. Similarly, other large panEuropean studies have described objectively measured physical activity patterns in children [8] and adolescents [7] using standardized methods. Results from these studies [4, 7, 8] consistently suggest that boys are more active than girls and that physical activity declines with increasing age. No previous study, however, has attempted to pool and harmonize all available accelerometer-measured physical activity data in European children and adolescents. Results from such a harmonized approach will provide a more comparable estimate of physical activity across studies which can be used to spur policymakers, governments, and local and national stakeholders to take action to facilitate structural changes aimed at increasing physical activity levels. Thus, the aim of this study was to assess the variations in physical activity and sedentary time by place and person in European children and youth. We used a systematic literature search and analysed personal level data using a harmonized approach including studies from 1997 to 2014.

\section{Methods}

Data sources, literature search and study selection

We identified published studies through a systematic review of six databases (PubMed, PsycINFO, EMBASE, Web of Science, Sport Discus, and Scopus) from database inception through March 16th, 2016. Updating the search through Sept 10th, 2017 did not reveal any new datasets.

The following search terms were used: "physical activity" OR "physical activities" OR "physically active" OR "physical exercise" OR "physical activity level" OR sedentary" OR Sedentari* OR "sitting" OR "physical inactivity" OR "physically inactive" AND "Acceleromet" OR "activity monitor" OR "motion sensor" OR "actigraph".

All retrieved records were imported into EndNote X7 (Thomson Reuters, New York). Duplicates were handsearched and removed. Records were included if they were written in the English language; included European study samples aged 2-18 years; and were cross-sectional studies, prospective cohort studies, or controlled trials that had assessed physical activity objectively using the ActiGraph accelerometer. In addition, studies were only included if they provided data from more than 400 individuals. One author (JSJ) extracted the following information from each eligible article: name of the first author, study location, number of participants, age, and physical activity assessment details.

\section{Data harmonization and data pooling}

We contacted the principal investigators of the studies eligible for inclusion and asked whether they were willing to participate in this study, reminding them once or twice if they did not respond. Data-sharing agreements were subsequently signed for studies that agreed to take part and raw accelerometer data files (e.g. .dat, GT3X) and descriptive data (country, age, sex, height, and weight) were transferred to the analytical team. For those studies already included in ICAD, data were made available according to the ICAD applications and authorship agreement (http://www.mrc-epid.cam.ac.uk/ research/studies/icad/).

The included studies had assessed physical activity using both uniaxial and triaxial hip-worn accelerometry (ActiGraph models 7164, GT1M, Actitrainer and GT3x/ $3 \mathrm{X}+$ ). For consistency across studies, we extracted data from the vertical axis only, reintegrated all files to $60 \mathrm{~s}$ epochs, and processed all data according to the 
suggested settings from ICAD 2.0 (http://www.mrc-epid. cam.ac.uk/research/studies/icad/) using the commercially available software KineSoft (v3.3.80, Loughborough, UK, http://www.kinesoft.org). Non-wear time was defined as $60 \mathrm{~min}$ of consecutive zeros allowing for 2 min of non-zero interruptions. To overcome challenges with different wear time protocols we excluded data recorded from 23:59 to 06:00 and all non-wear time, we considered days with $\geq 480$ min of activity recordings as valid. Repeated measurements of a child were regarded as multiple individuals.

Average counts per minute (CPM) were used as a measure of total physical activity. Evenson cut-points [10] were used to define light- (101 to $\geq 2295)$, moderate( $\geq 2296 \mathrm{CPM})$, and vigorous-intensity ( $\geq 4012 \mathrm{CPM})$ physical activity. These cut points show the best overall performance across all intensity levels [11] and suggested as the most appropriate cut points for youth [12]. For descriptive purposes, we defined time spent sedentary as all-time (min) spent $\leq 100 \mathrm{CPM}$. The numbers of minutes per day in different intensities were determined by summing all minutes where the activity count were equal to and greater than the threshold for that intensity, divided by the number of valid days. Irrespective of age, participants achieving on average $\geq 60 \mathrm{~min}$ of MVPA per valid day were defined as being sufficiently physically active.

\section{Anthropometry}

Trained personnel measured height and weight using standardized techniques across studies. We calculated body mass index (BMI) as weight (in kilograms) divided by height (in meters) squared. For descriptive purposes, we further categorized individuals as normal weight, overweight, and obese based on age- and sex-specific cut-offs [13]. A small number of participants was categorized as underweight $(8 \%)$ and combined with the normal weight group.

Local ethics committee approval, parental/legal guardian consent, and child assent were obtained in all studies.

\section{Statistical analyses}

All analyses were conducted in Stata 13.1 (StataCorp., 2013. Stata Statistical Software: TX: StataCorp LP). Descriptive statistics were used to assess sample characteristics as well as levels of physical activity and sedentary time. Multivariable regression analyses, stratified by children (age $<10 \mathrm{y})$ and adolescents $(\geq 10 \mathrm{y})$, were used to compare total physical activity levels (CPM), MVPA, and sedentary time between countries and across European regions (i.e. north, west, east and south) as demarcated by the United Nations (https://unstats.un.org/unsd/ methodology/m49/). Due to lack of countries (only Hungary) to cover the eastern region we merged west and east to central Europe. Multivariable logistic regression analyses were conducted to estimate the odds ratios (ORs) for those defined as sufficiently physically active across sexes, BMI categories, and regions of Europe. To obtain an overall European weighted prevalence estimate we used prevalence estimates from each country weighted by the square root of number of participants within each country. We performed sensitivity analyses by excluding participants from the two largest cohorts one at a time (ALSPAC and IDEFICS) and subsequently participants from the UK and repeated analyses. As participants were recruited from different studies across different countries, we used "study" as a cluster variable in all models to obtain robust variance estimations. Moreover, sex, age, country, season, study year, ActiGraph model, and wear time (where appropriate) were included as covariates in all analyses. Statistical significance was set at $p<.05$.

\section{Role of founding source}

The study sponsors were not involved in study design; in the collection, analysis, and interpretation of data; in the writing of the report; and in the decision to submit the paper for publication. The corresponding author had full access to data in the study and had final responsibility for the decision to submit for publication.

\section{Results}

In total, 2231 articles were identified by the literature search. We retrieved 79 papers for full-text review, of which 37 studies were identified as eligible for inclusion (Fig. 1). The principal authors of these studies were contacted regarding their willingness to contribute to the harmonized pooled analyses by sharing their data. Twenty-nine [14-37] of the 37 studies' authors agreed, whereas the remaining eight [38-46] either refused to participate or did not respond to our requests. We additionally obtained data from one previously unpublished Portuguese study. Thus, 30 studies including 18 countries and 51,828 individuals aged $2-18$ years were eligible for the harmonized pooled analyses. Of these, accelerometer data were missing from 1879 individuals.

After reanalysis, 48,242 of 49,949 eligible files (96.6\%) were deemed valid (Table 1). Reasons for exclusion included: zero days with a wear time of $<480 \mathrm{~min}$ and no data on file $(n=1534)$ and monitor malfunction $(n=$ 173). In addition, 745 individuals were missing descriptive data (country, sex, age, weight, or height), leaving a total sample of 47,497 individuals included in the present analyses. On average, the included participants provided $5(1.7 \mathrm{SD})$ valid days of measurement and 12.9 (1.7 SD) hours of wear time per valid day. Girls were slightly overrepresented (52\% of participants), as were data from participants aged 7-15 years (75\%) and 


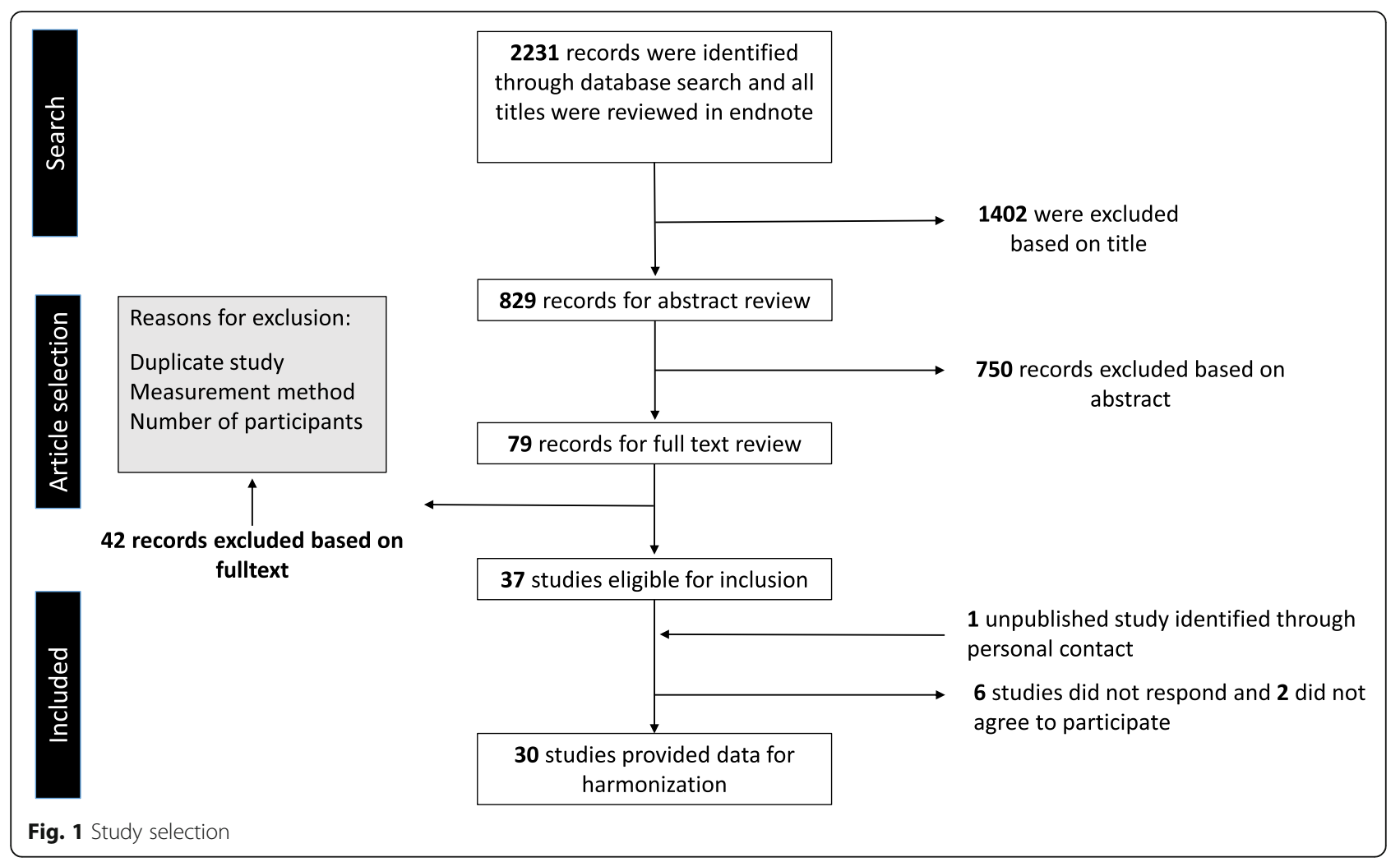

participants from the UK (39\%). Fifteen percent of the sample was classified as overweight and 5\% as obese. Supplementary descriptive characteristics of the analytical sample by country are summarized in Additional file 1.

\section{Comparison across sex and age}

In general, participants spent $49.2 \%$ of their measured time sedentary, $44.4 \%$ being light physically active, and $6.4 \%$ being physically active with moderate to high intensity (MVPA). In both age groups, boys were more active (children: $13 \mathrm{~min}$ MVPA/day, 95\% CI: 12, 14; adolescents: $17 \mathrm{~min} /$ day, $95 \% \mathrm{CI}: 16,18)$ and spent less time sedentary compared to girls (children: $8 \mathrm{~min} /$ day, $95 \%$ CI: 6, 11; adolescents $22 \mathrm{~min} /$ day, 95\% CI: 19, 25 for adolescents). Average CPM as well as intensity-specific activity (MVPA and sedentary time) were significantly associated with age. Categorizing male and female participants into eight age categories $(2-3,4-5,6-7,8-9$, $10-11,12-13,14-15$, and 16-17) suggested substantial age group differences in average CPM. Counts per minute were highest at ages $4-5$ years and were then progressively lower in every age group until ages 14-15 years, with an average category-to-category difference of 54 CPM. The most pronounced difference was observed between ages $6-7$ and $8-9$ years (-101 CPM, 95\% CI: 197, -6). Time spent in MVPA was highest at ages 6-7 years and was progressively lower by increasing age groups, with an average difference of $2.8 \mathrm{~min} /$ day by age category. Time spent sedentary (min/day) increased progressively from ages $4-5$ years to $16-17$ years (Fig. 2, ac). Females, overweight and obese participants, showed significantly lower odds of being categorized as sufficiently physically active (Table 3 ).

\section{Comparison across countries}

The prevalence of being categorized as sufficiently active (i.e. accumulating an average of $\geq 60 \mathrm{~min} /$ day of MVPA) by region, country, and age group is shown in Table 2 and Fig. 3a and b. Overall, weighted estimates suggested that $29 \%$ (95\% CI: 25,33$)$ of children and $29 \%$ (95\% CI: 25,32 ) of adolescents were categorized as sufficiently physically active as defined by an average of at least 60 min MVPA per day. In sensitivity analyses, excluding participants from the two largest cohorts one at a time (ALSPAC and IDEFICS) and subsequently participants from the UK had only a minor impact on prevalence estimates (a $1-3 \%$ reduction in prevalence, data not shown). Across regions, the highest prevalence of sufficiently active was observed in Northern European countries with significant lower estimates in SouthernEuropean countries. The prevalence of those defined as sufficiently active was highest living in Northern Europe (31\%) compared to Central Europe (26\%) and those living in Southern Europe (23\%). As illustrated in Table 2, there were substantial differences in prevalence estimates across countries, with the highest estimates recorded in Swiss 
Table 1 Studies in alphabetic order: country of origin, design and characteristics of study participants included in the present analyses

\begin{tabular}{|c|c|c|c|c|c|c|c|c|}
\hline Study Name & Yrs & Months & Country & Design & Files $^{a}$ & Age $(y)$ & Model & Epoch \\
\hline ALSPAC & $2003-07$ & All & United Kingdom & Long. & 10,426 & $10-15$ & $\begin{array}{l}\text { 7164, 71,256, } \\
\text { GT1M }\end{array}$ & 60 \\
\hline Ballabeina Study & 2008-09 & June-Sept & Swiss & Inter. & 998 & $4-8$ & GT1M & 15 \\
\hline Belgium Pre-School Study & 2006;08-09 & Oct-March & Belgium & CS & 170 & $3-7$ & GT1M & 15 \\
\hline CHASE & $2006-07$ & Jan-Feb & United Kingdom & CS & 2011 & $9-10$ & GT1M & 15 \\
\hline COsCls & $2001-05$ & Oct-May & Denmark & Inter. & 1146 & $6-11$ & 7164 & 60 \\
\hline EYHS (Denmark) & $\begin{array}{l}\text { 1997-98; } \\
\text { 2003-04 }\end{array}$ & All & Denmark & Long. & 1715 & $8-18$ & 7164 & 60 \\
\hline EYHS (Estonia) & 1998-99 & Aug-May & Estonia & CS & 660 & $8-17$ & 7164 & 60 \\
\hline EYHS (Norway) & 1999-00 & Feb-Oct & Norway & CS & 387 & $9-10$ & 7164 & 60 \\
\hline EYHS (Portugal) & 1999-00 & Jan-July & Portugal & Long. & 1357 & $8-18$ & 7164 & 60 \\
\hline EYHS SPAIN & 2008-10 & - & SPAIN & CS & 447 & $8-10$ & GT1M & 15 \\
\hline GINI & 2011-14 & All & Germany & CS & 1220 & $14-17$ & GT3X & 60 \\
\hline Helena & $2006-07$ & All & $\begin{array}{l}\text { Austria, Belgium, France, Germany, } \\
\text { Greece, Hungary, Italy, Spain, Sweden }\end{array}$ & CS & 2755 & $13-17$ & GT1M & 15 \\
\hline IDEFICS & $2007-2010$ & Sept-May & $\begin{array}{l}\text { Italy, Estonia, Cyprus, Belgium. } \\
\text { Sweden, Germany, Hungary, Spain }\end{array}$ & Long & 7104 & $2-9$ & $\begin{array}{l}\text { GT1M/ } \\
\text { Actitrainer }\end{array}$ & 15,60 \\
\hline ISCOLE & $2011-13$ & All & Finland & CS & 531 & $9-11$ & GT3X & 15 \\
\hline KISS & 2005-06 & May-Nov & Swiss & Inter. & 889 & $6-14$ & 7164, GT1M & 60 \\
\hline LISA & $2011-14$ & All & Germany & CS & 429 & $14-16$ & GT3X & 60 \\
\hline MAGIC & $2006-07$ & Nov-May & United Kingdom & CS & 434 & $3-4$ & 7164 & 60 \\
\hline MAL-TA & 2012 & Jan-May & Malta & CS & 859 & $10-11$ & GT3X & 10 \\
\hline Odense Preschool & 2009 & May-June & Denmark & CS & 527 & $5-6$ & GT1M/GT3X & 10 \\
\hline OPUS & 2011 & Aug-Nov & Denmark & Long & 705 & $8-11$ & GT3X (+) & 60 \\
\hline PANCS & 2005-06 & All & Norway & CS & 2031 & $9-15$ & 7164 & 10 \\
\hline PEACH & 2006-09 & Sept-July & England & Long. & 2088 & $10-13$ & GT1M & 15 \\
\hline Portugal & 2008-09 & All & Portugal & CS & 2557 & $10-18$ & GT1M & 15 \\
\hline Prestyle & 2009 & - & Portugal & CS & 567 & $3-6$ & GT1M & 5 \\
\hline ProActive & 2012-13 & - & United Kingdom & CS & 1207 & $10-11$ & GT3X & 15 \\
\hline Portugal & 2010-11 & Sept-June & Portugal & CS & 660 & $11-12$ & GT1M & 30 \\
\hline SPACE & 2010 & Apr-June & Denmark & Inter. & 1274 & $11-13$ & GT3X & 30 \\
\hline SPEEDY & 2007 & Feb-July & United Kingdom & $\mathrm{CS}$ & 1992 & $9-11$ & GT1M & 5 \\
\hline $\begin{array}{l}\text { The Belgian Environmental PA } \\
\text { study in Youth }\end{array}$ & 2008-09 & Oct-May & Belgium & CS & 606 & $13-15$ & GT1M & 60 \\
\hline The Gateshead Millennium Study & 2006-07 & Oct-Dec & United Kingdom & Cross & 478 & $6-8$ & GT1M & 15 \\
\hline The Gateshead Millennium Study & 2006-07 & Oct-Dec & United Kingdom & Cross & 478 & $6-8$ & GT1M & 15 \\
\hline
\end{tabular}

ALSPAC Avon Longitudinal Study of Parents and Children; CHASE Child Heart And Health Study in England; GINIplus German Infant Study on the influence of Nutrition Intervention PLUS environmental and genetic influences on allergy development; HELENA Healthy Lifestyle in Europe by Nutrition in Adolescence Study; IDEFICS Identification and prevention of Dietary- and lifestyle-induced health EFfects In Children and infantS; ISCOLE The International Study of Childhood Obesity, Lifestyle and the Environment KISS, Kinder-Sportstudie; LISA Influence of Life-style factors on the development of the Immune System and Allergies in East and West Germany; MAGIC Movement and Activity Glasgow Intervention in Children; MAL-TA Movement, Activity and Lifestyle- tweens in action; PEACH Personal and Environmental Associations with Children's Health; SPEEDY Sport, Physical activity and Eating behaviour: Environmental Determinants in Young people; SPACE, aalid files included in analyses

children (38, 95\% CI: 25, 51) and Swiss adolescents (43, 95\% CI: 37, 48). The lowest prevalence estimates were observed participants in Southern European countries, where only 13\% (95\% CI: 9, 16) of Cypriot children and $14 \%$ of Maltese adolescents were sufficiently active.
Average CPM and time spent sedentary and in MVPA varied substantially between countries in both younger and older age groups (Additional file 3). Among children, the difference between the least active (Cyprus) and most active (Norway) countries for total PA was 169 

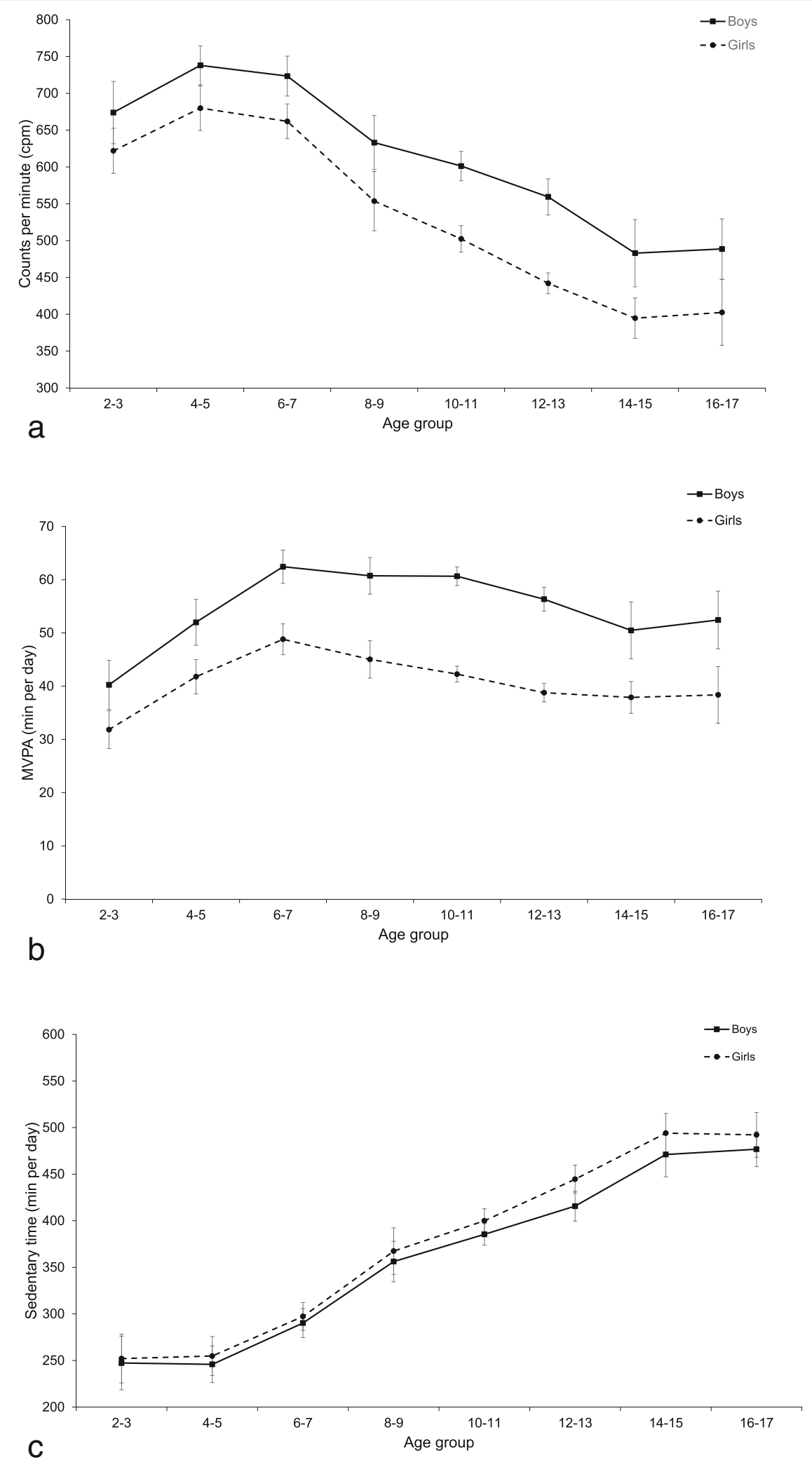

Fig. 2 a-c. Predicted physical activity level ( $95 \%$ Cl) by age and sex for a) total physical activity (CPM); b) time spent in moderate to vigorous (MVPA) and c) time spent sedentary (SED). All estimates are adjusted for wear time (b and c), country, season, study year and ActiGraph models 
Table 2 Prevalence $(95 \% \mathrm{Cl}$ ) of for being categorized as sufficiently physically active by European region, country and age group

\begin{tabular}{|c|c|c|c|c|}
\hline European region & Overall region & Country within region & Children (2-9.9 y) & Adolescents ( $\geq 10-18$ y) \\
\hline \multirow[t]{6}{*}{ North $(n=28,988)$} & $31(29,34)$ & Norway & $37(26,49)$ & $34(32,37)$ \\
\hline & & Sweden & $33(28,39)$ & $38(31,44)$ \\
\hline & & Denmark & $32(24,41)$ & $29(21,37)$ \\
\hline & & Finland & $25(11,38)$ & $29(15,43)$ \\
\hline & & Estonia & $28(23,32)$ & $40(29,52)$ \\
\hline & & UK & $31(21,40)$ & $30(27,32)$ \\
\hline \multirow[t]{6}{*}{ Central $(n=9287)$} & $26(20,32)$ & France & N/A & $28(23,33)$ \\
\hline & & Germany & $33(28,38)$ & $24(10,38)$ \\
\hline & & Austria & N/A & $34(27,40)$ \\
\hline & & Swiss & $38(25,51)$ & $43(37,48)$ \\
\hline & & Belgium & $18(10,26)$ & $20(16,23)$ \\
\hline & & Hungary & $22(19,25)$ & $38(31,46)$ \\
\hline \multirow[t]{6}{*}{ South $(n=9222)$} & $23(20,27)$ & Portugal & $25(21,29)$ & $24(19,29)$ \\
\hline & & Spain & $25(21,28)$ & $33(29,37)$ \\
\hline & & Italy & N/A & $21(17,26)$ \\
\hline & & Malta & N/A & $14(10,19)$ \\
\hline & & Cyprus & $13(9,16)$ & N/A \\
\hline & & Greece & N/A & $27(22,33)$ \\
\hline
\end{tabular}

All estimates are adjusted for sex, age, wear time, country, season, study year and ActiGraph models. Study used as cluster variable

CPM (95\% CI: 55, 283), which corresponds to a difference in accelerometer output of $24 \%$. In adolescents, similar differences (141 CPM, 95\% CI: 73, 210) were observed between the most active (Norwegians) and least active (Maltese). Northern European countries (Norway, Estonia, the UK, Sweden, and Denmark) recorded the highest levels of total PA regardless of age. We observed similar differences between countries when we repeated the analyses using time spent (minutes/day) in MVPA and sedentary time as outcomes. In children, participants from Cyprus spent on average 19 (95\% CI: 8, 31) fewer minutes in MVPA per day compared to their Norwegian counterparts, whereas in the oldest age group, the Maltese adolescents spent on average 25 (95\% CI: 16, 33) fewer minutes in MVPA compared to the Swiss participants. The Finnish children and Belgian adolescents spent the most amount of time sedentary.

We observed a significant north-south MVPA gradient $(p=.001)$, with Southern European and Central European participants having an odds ratio for being sufficient physical active at 0.63 and 0.75 , respectively, compared to participants from the Northern Europe (Table 3). Southern European participants spent an average of $5 \mathrm{~min}$ (95\% CI: 2, 9) per day in MVPA less than participants from Northern Europe. There was no difference in time spent in MVPA between Northern and Central European participants. The same significant north-south gradient was also evident for total physical activity and sedentary time, showing average differences of 34 CPM $(95 \% \mathrm{CI}: 18,49)$ and 15 min sedentary time per day $(95 \% \mathrm{CI}: 6,22)$ when moving from one region to another (Additional file 2).

\section{Discussion}

These analyses-including data from more than 47,000 young people across 18 European countries-indicate that overall physical activity, time spent in MVPA, sedentary time, and prevalence of being sufficiently physical active differ substantially between countries and regions. We observed a north-south gradient showing lower physical activity levels and more time spent sedentary among Southern European participants. Indeed, the prevalence of those defined as sufficiently active was lower among those living in Southern Europe (23\%) compared to those living in Northern Europe (31\%).

Differences in physical activity and sedentary time between countries have consistently been described in the literature $[5,6]$; it has been proposed, however, that much of this variation is likely due to methodological differences related to the reduction, processing, and analysis of accelerometer data. Our harmonized analyses allowed us to compare physical activity levels across countries with greater accuracy and precision in a larger and more diverse European population than has previously been possible $[4,7,8]$. The substantial differences between countries are similar to previous results from other pan-European cohorts including device-based measures of activity $[4,7,8]$. The observed $30-35 \%$ 


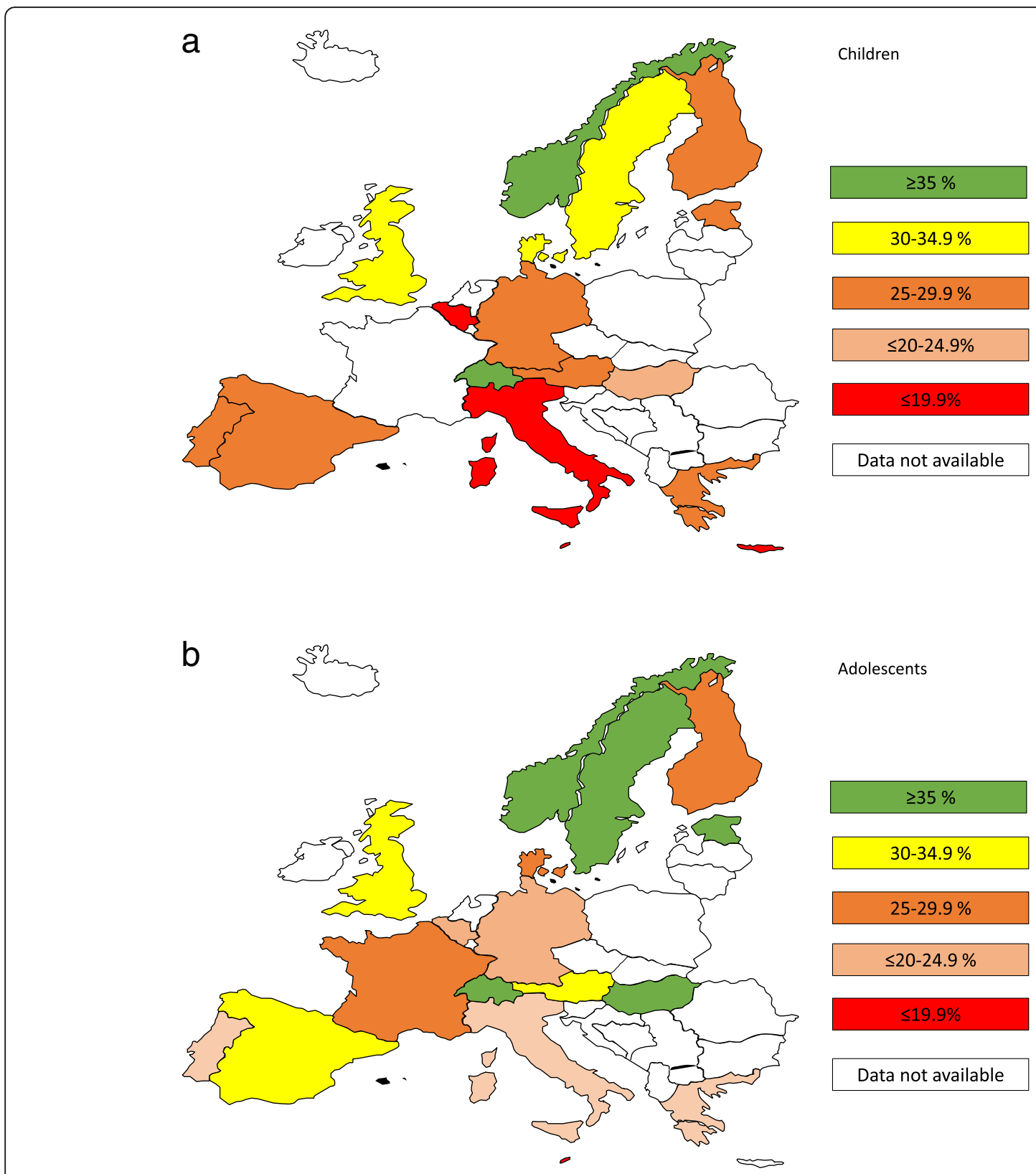

Fig. 3 a Prevalence categories ( $\leq 19.9 \%, 20 \cdot 0-24.9 \%, 25 \cdot 0-29.9 \%, 30 \cdot 0-34.9 \%$ and $\geq 35 \%$ ) of children being sufficiently physical active by country. b Prevalence categories ( $\leq 19.9 \%, 20 \cdot 0-24 \cdot 9 \%, 25 \cdot 0-29 \cdot 9 \%, 30 \cdot 0-34.9 \%$ and $\geq 35 \%$ ) of adolescents being sufficiently physical active by country

difference in total physical activity level (CPM) between the most and least active countries indicates substantial variation in physical activity levels in European youth.

Based on analyses stratified by region (north, central, and south; see Additional file 2), we observed higher levels of physical activity (CPM and MVPA) and lower time spent sedentary among Northern European individuals compared to those living in Southern Europe. This north-south gradient, where individuals living in Southern Europe were $64 \%$ less likely to be classified as sufficiently physically active compared to their peers living in
Northern Europe. This pattern was consistent across age and independent of body mass index BMI (data not shown). Based on pan-European data, Ruiz et al. [7] observed differences in physical activity patterns in centralNorthern versus Southern European adolescents. The differences between regions, however, were less pronounced compared to those reported here, possibly explained by a smaller sample size, more narrow age span (aged 10-18 years) and only included data from nine countries. A similar north-south gradient have also been observed in a study by Konstabel et al. [8] but only 
Table 3 Odds ratio (95\% Cl) for being categorized as physically active by sex, weight status and European region

\begin{tabular}{|c|c|c|c|c|c|c|}
\hline & \multicolumn{2}{|l|}{ Total } & \multicolumn{2}{|c|}{ Children } & \multicolumn{2}{|c|}{ Adolescents } \\
\hline & $\%$ & OR $(95 \% \mathrm{Cl})$ & $\%$ & OR $(95 \% \mathrm{Cl})$ & $\%$ & OR $(95 \% \mathrm{Cl})$ \\
\hline Overall ${ }^{a}$ & & $\mathrm{~N} / \mathrm{A}$ & $28 \cdot 7$ & & 28.9 & \\
\hline \multicolumn{7}{|l|}{ Sex } \\
\hline Male (ref) & $40 \cdot 6$ & 1.00 & $38 \cdot 7$ & & $41 \cdot 8$ & \\
\hline Female & $18 \cdot 0$ & $0.30(0.26,0.35)$ & $20 \cdot 2$ & $0.37(0.31,0.44)$ & $16 \cdot 6$ & $0.26(0.23,0.29)$ \\
\hline \multicolumn{7}{|l|}{ Weight status } \\
\hline Normal (ref) & $30 \cdot 5$ & 1.00 & $30 \cdot 8$ & 1.00 & $30 \cdot 5$ & 1.00 \\
\hline Overweight & $23 \cdot 6$ & $0.68(0.61,0.76)$ & $24 \cdot 6$ & $0.71(0.61,0.82)$ & $22 \cdot 4$ & $0.62(0.54,0.72)$ \\
\hline Obese & $19 \cdot 3$ & $0.51(0.42,0.63)$ & $18 \cdot 6$ & $0.48(0.36,0.63)$ & 18.5 & $0.48(0.38,0.61)$ \\
\hline \multicolumn{7}{|c|}{ European region } \\
\hline North (ref) & $31 \cdot 4$ & 1.00 & $31 \cdot 3$ & 1.00 & 29.9 & 1.00 \\
\hline Central & $26 \cdot 0$ & $0.75(0.51,1.01)$ & $29 \cdot 4$ & $0.90(0.63,1.27)$ & 28.5 & $0.93(0.56,1.54)$ \\
\hline South & $23 \cdot 2$ & $0.63(0.50,0.79)$ & $23 \cdot 8$ & $0.65(0.51,0.83)$ & $23 \cdot 4$ & $0.69(0.51,0.93)$ \\
\hline
\end{tabular}

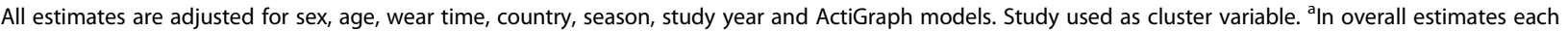
country weighted by the square root of participants within each country

including children in pre- and primary school from eight countries. Thus, our results provide a more comprehensive description of physical activity levels among European children and adolescents which suggests that regional differences observed are unlikely explained by differences in methods used. Possible explanations for the apparent north-south gradient remain unclear and further studies including harmonized data on objectively assessed physical activity in combination with individual, social, and environmental data on determinants of physical activity (and sedentary time) are needed $[4,5]$-for example, cultural differences and the extent to which physical activity policies are developed and prioritized within countries may influence physical activity levels. Thus, the results presented are of importance for regional, national, and European policymakers in facilitating implementations of programs aimed at increasing physical activity in all European children and adolescents.

In total, $29 \%$ of the study population was categorized as sufficiently physically active. In comparison, Cooper et al. [4] reported a significantly lower prevalence estimate based on ICAD data, with only $9 \%$ of boys and $2 \%$ of girls achieving the recommended activity levels. Discrepancies between estimates are not only explained by the different MVPA cut-point used, but also the interpretation of guideline adherence. Cooper et al. [4] used conservative criteria requiring participants to accumulate $\geq 60 \mathrm{~min}$ of MVPA on every measured day, whereas we used more liberal criteria in which accumulating on average $\geq 60 \mathrm{~min}$ of MVPA per day during the measurement period was deemed sufficient. Both guidelineadherence interpretations have been used in multinational studies in children and adolescents $[4,7,8,47$, 48] and highlights one of the major challenges when comparing data using different interpretations. Interestingly, Cooper et al. [4] also provided data using a more liberal interpretation, showing that $\geq 60 \mathrm{~min}$ of MVPA was accumulated on $46 \%$ of days for boys and $22 \%$ for girls. These results, although not directly comparable, are more in line with our own estimates; regardless, we report that at least two-thirds of European children and adolescents are insufficiently active and should be of concern for public health authorities.

Our observations corroborate previous findings $[4,7,8]$ showing that boys are more active than girls and that differences in activity increase with age. The cross-sectional agerelated negative trend in physical activity observed in the present study is a commonly reported finding; however, some discrepancies exist regarding the onset of this trend $[4,49,50]$. In cross-sectional analyses, Cooper et al. [4] observed gradually lower activity levels starting from ages 5 6 , whereas a previous systematic review and pooled analyses from longitudinal studies [49] concluded that physical activity declines with the onset of adolescence. However, only 2 of the 26 studies used device-based measures and most studies were conducted before the year 2000. Thus, the generalizability to contemporary populations might be questionable. Farooqa et al. [50] recently presented longitudinal analyses from the Gateshead Millennium Cohort Study reporting a marked decline in physical activity during childhood (from age 7 years to 15 years).

In this line, we observed that the onset of age-related lowering or leveling-off of physical activity seems to occur at around 6 to 7 years of age. Taken together, the transition between early childhood (preschool) and childhood (primary school) appears to be a critical period where interventions aimed at preventing a decline in physical activity are important; nonetheless, there is still a need for 
more longitudinal cohort studies describing changes in device-based measured physical activity across childhood, adolescence, and even the transition to young adulthood.

\section{Strengths and limitations}

The main strength of this study is the use of individuallevel accelerometer data, harmonized (i.e. cleaned, processed, and re-analyzed) in a consistent manner, across studies. This is by far the largest harmonized individual physical activity dataset including a wide age range (218 years) and individuals from 18 European countries.

Some limitations should also be acknowledged. First, differences in recruitment and sampling methodology within cohorts and between studies likely limit the representativeness to fully reflect the true prevalence of physical activity. Thus, it is possible that the observed differences between countries are due to incorrect representation of the actual demographic distribution within a country. For example, it seems that participants in some studies are less likely to be overweight or obese than the general population [51]. Given the inverse association between BMI and physical activity, we cannot rule out that these participants may be more active than the general population; thus, the true physical activity levels and physical activity prevalence estimates may be somewhat overestimated in this study. The choice to only include studies with more than 400 individuals could be considered arbitrary, however this was done to increase the possibility of representativeness for each country. Second, differences in data collection procedures may have influenced the results and thus may partly explain the observed differences between countries. For instance, some studies used a 24-h protocol, a four-day protocol, whereas others assessed physical activity for at least 7 days and the sampling of weekdays and weekend days may be different within and between studies. To overcome some of these limitations, we excluded data recorded from 23:59 to 06:00, adjusted for monitor wear time and used "study" as a cluster variable in all analyses. However, we cannot rule out that for some individuals, in those studies employing a $24 \mathrm{~h}$ - hour protocol, sedentary time might have been overestimated.

The accelerometer thresholds and the selection of epoch length should also be considered. It is wellestablished that these decisions have a substantial impact on physical activity intensity outcomes (e.g. time spent in MVPA) when assessing adherence to physical activity recommendations. Thresholds for intensity levels used in the present study are in line with a previous multicountry study [4] and have been shown to provide valid estimates for children and adolescents [10]. Age-specific thresholds have been developed for toddlers aged 2 to 5 years $[52,53]$. These thresholds are, however, developed based on shorter epochs (5-15s) and it is unclear whether these are applicable to the 60-s epoch used in the analyses herein. Thus, we have not included agespecific cut points for those under the age of 5 years, which might result in underestimation of time spent in MVPA for this age-group. Anyhow, sensitivity analyses excluding all participants $<5$ years of age $(N=3348,7 \%$ of the total sample) revealed only minor changes in the prevalence estimates, indicating that our main conclusion, suggesting a northern-southern gradient, is valid (Additional file 5). A short epoch length (e.g. $10 \mathrm{~s}$ ) is the preferred option in young people [12]; however, we used a 60-s epoch for the purpose of data harmonization, as some of the studies we included collected their data using this epoch length. This may lead to misclassification of MVPA as light physical activity, less time accumulated in MVPA and subsequently an underestimation of the prevalence of being categorized as physically active. Including cohorts spanning a relatively long time period (1997-2015) introduces a potential bias due to the use of different ActiGraph models. To date, newer generations of ActiGraphs, i.e. from the GT1M and forward, can be compared and used interchangeably [54] but comparability with the older 7164 model is unclear [55]. Nevertheless, including "ActiGraph model" as a covariate had a substantial impact on our results, as the regression models showed higher physical activity outputs (CPM and MVPA) with the oldest model (7164) compared to the newer models (GT1M, GT3X) (Additional file 4). However, the study design of the present study does not allow exploring to what extent differences in physical activity outputs could be explained by model used. Thus, we cannot rule out that adjustment for model might have led to both underestimation (7164) and overestimation (GT1M, GT3X) of the true physical activity level. Nonetheless, sensitivity analyses excluding "ActiGraph model" from the regression model did not change the ranking of countries or regions for any of the outcomes. Taken together, the present results should be interpreted in light of the abovementioned limitations.

Third, a known limitation of accelerometers is their inability to capture certain movements, such as cycling, which may differ substantially between countries. There is some evidence suggesting that that physical activity during cycling as transportation is substantially underestimated when using accelerometers [56]. Thus, in countries with a high prevalence of cycling for transportation such as Belgium and Denmark, physical activity levels may therefore have been underestimated in these countries. In addition, hip-mounted accelerometers cannot measure posture and distinguish between sitting and standing, thus our estimates of sedentary time may include both sitting and standing still. Fourth, we defined prevalence of sufficiently active as an average of $60 \mathrm{~min}$ per day due to differences between studies in protocols. 
Thus, our prevalence estimates may be overestimated. Furthermore, we did not distinguish between toddlers (1-5 years old), children, and adolescents when applying our definition of being sufficiently active. Some countries have proposed separate physical activity guidelines for children < 5 years stating that they should be physically active (at any intensity) for at least $180 \mathrm{~min}(3 \mathrm{~h})$ daily, spread throughout the day. Although, the evidence for a causal association between physical activity and health in children and adolescents is limited and obtained from predominantly observational research compared with that for adults, there is growing evidence that MVPA is associated with greater health benefits than lower intensity activity [2]. Thus, we consider time spent in MVPA more relevant when defining sufficiently active individuals, although acknowledging that this is affected by the choice of cut points to define MVPA.

Fifth, it is well-known that children's activity levels exhibit a seasonal pattern [57], and weekly pattern [58] with lower levels during the winter months when cold weather and reduced daylight is suggested to reduce physical activity [59]. Thus, we cannot rule out that seasonality, weekly pattern, weather, and temperature may have affected our results; on the other hand, the majority of the included studies collected data over several months covering multiple seasons, and we included season as a covariate in all analyses.

Finally, the relatively large timespan between the earliest (1999) and latest (2016) data collections needs to be considered; one may speculate that the observed differences between countries and European regions could be explained by secular trends with decreased physical activity levels over time. However, our data did not reveal any significant association between any physical activity outcome and study year (data not shown) and there is little evidence for any secular trends in physical activity during the last decades $[60,61]$.

Although the present harmonized individual-level accelerometer data does increase comparability between studies, the abovementioned limitations highlight the need for more standardized data collection, including a setup for large pan-European surveillance of physical activity and sedentary time using accelerometry.

\section{Conclusion}

Our pan-European data show that more than twothirds of European youth can be categorized as insufficiently active. Our findings also suggest substantial country- and region-specific differences in physical activity reaching up to $30-35 \%$ differences in total physical activity (CPM) between the least and most active countries, with a clear trend of lower levels in Southern compared to Northern regions, i.e., $23 \%$ vs.
$31 \%$ of participants meeting the physical activity recommendations respectively. These results should urge policymakers, governments, and local and national stakeholders to immediately facilitate structural and political changes to promote physical activity in European youth.

\section{Supplementary information}

Supplementary information accompanies this paper at https://doi.org/10. 1186/s12966-020-00930-x.

\begin{abstract}
Additional file 1. Descriptive characteristics (mean, SD) of study participants by country. This table describes proportion of boys and girls, age and weight status within each country
\end{abstract}

Additional file 2. Accelelloremeter-assessed physical activity and sedentary time by region for the total sample and based on ages $<10$ and $\geq$ 10. This table describes physical activity and sedentary time by region North, West and East

Additional file 3. Predicted time spent per day in total physical activity, moderate to vigorous PA and sedentary by country and stratified by children and adolescents.

Additional file 4. Physical activity outputs (CPM and MVPA) by "ActiGraph model".

Additional file 5. Odds ratio $(95 \% \mathrm{Cl})$ for being categorized as physically active by European region excluding participants $<5$ years $(n=3348)$

\section{Acknowledgments}

We would like to thank all participants and funders of the original studies that contributed data to this joint effort. The preparation of this paper was supported by the Determinants of Diet and Physical Activity knowledge hub (DEDIPAC). This work is supported by the European Union Joint Programming Initiative "Healthy Diet for a Healthy Life."

We would like to thank all participants and funders of the original studies that contributed data to ICAD. T We also gratefully acknowledge the contribution of Prof Chris Riddoch, Prof Ken Judge, Prof Ashley Cooper and Dr. Pippa Griew to the development of ICAD.

The ICAD Collaborators include: Prof LB Andersen, Department of Teacher Education and Sport, Western Norwegian University of Applied Sciences, Sogndal, Norway (Copenhagen School Child Intervention Study (CoSCIS)); Prof S Anderssen, Norwegian School for Sport Science, Oslo, Norway (European Youth Heart Study (EYHS), Norway); Dr. AJ Atkin, Faculty of Medicine and Heath Sciences, University of East Anglia, UK; Prof G Cardon, Department of Movement and Sports Sciences, Ghent University, Belgium (Belgium Pre-School Study); Centers for Disease Control and Prevention (CDC), National Center for Health Statistics (NCHS), Hyattsville, MD USA (National Health and Nutrition Examination Survey (NHANES)); Dr. R Davey, Centre for Research and Action in Public Health, University of Canberra, Australia (Children's Health and Activity Monitoring for Schools (CHAMPS)); Prof U Ekelund, Norwegian School of Sport Sciences, Oslo, Norway \& MRC Epidemiology Unit, University of Cambridge, UK; Dr. DW Esliger, School of Sports, Exercise and Health Sciences, Loughborough University, UK; Dr. P Hallal, Postgraduate Program in Epidemiology, Federal University of Pelotas, Brazil (1993 Pelotas Birth Cohort); Dr. BH Hansen, Norwegian School of Sport Sciences, Oslo, Norway; Prof KF Janz, Department of Health and Human Physiology, Department of Epidemiology, University of lowa, lowa City, US (lowa Bone Development Study); Prof S Kriemler, Epidemiology, Biostatistics and Prevention Institute, University of Zürich, Switzerland (Kinder-Sportstudie (KISS)); Dr. N Møller, University of Southern Denmark, Odense, Denmark (European Youth Heart Study (EYHS), Denmark); Dr. K Northstone, School of Social and Community Medicine, University of Bristol, UK (Avon Longitudinal Study of Parents and Children (ALSPAC)); Dr. A Page, Centre for Exercise, Nutrition and Health Sciences, University of Bristol, UK (Personal and Environmental Associations with Children's Health (PEACH)); Prof R Pate, Department of Exercise Science, University of South Carolina, Columbia, US (Physical Activity in Pre-school Children (CHAMPS-US) and Project Trial of Activity for Adolescent Girls (Project TAAG)); Dr. JJ Puder, Service of Endocrinology, 
Diabetes and Metabolism, Centre Hospitalier Universitaire Vaudois, University of Lausanne, Switzerland (Ballabeina Study); Prof J Reilly, Physical Activity for Health Group, School of Psychological Sciences and Health, University of Strathclyde, Glasgow, UK (Movement and Activity Glasgow Intervention in Children (MAGIC)); Prof J Salmon, Institute for Physical Activity and Nutrition (IPAN), School of Exercise and Nutrition Sciences, Deakin University, Geelong, Australia (Children Living in Active Neigbourhoods (CLAN) \& Healthy Eating and Play Study (HEAPS)); Prof LB Sardinha, Exercise and Health Laboratory, Faculty of Human Movement, Universidade de Lisboa, Lisbon, Portugal (European Youth Heart Study (EYHS), Portugal); Dr. LB Sherar, School of Sports, Exercise and Health Sciences, Loughborough University, UK; Dr. EMF van Sluijs, MRC Epidemiology Unit \& Centre for Diet and Activity Research, University of Cambridge, UK (Sport, Physical activity and Eating behaviour: Environmental Determinants in Young people (SPEEDY))."

The authors thank all the families for their participation in the GINIplus study. Furthermore, we thank all members of the GINIplus Study Group for their excellent work. The GINIplus Study group consists of the following: Institute of Epidemiology I, Helmholtz Zentrum München, German Research Center for Environmental Health, Neuherberg (Heinrich J, Brüske I, Schulz H, Flexeder C, Zeller C, Standl M, Schnappinger M, Ferland M, Thiering E, Tiesler C); Department of Pediatrics, Marien-Hospital, Wesel (Berdel D, von Berg A); Ludwig-Maximilians-University of Munich, Dr. von Hauner Children's Hospital (Koletzko S); Child and Adolescent Medicine, University Hospital rechts der Isar of the Technical University Munich (Bauer CP, Hoffmann U); IUF- Environmental Health Research Institute, Düsseldorf (Schikowski T, Link E, Klümper C, Krämer U, Sugiri D).

The authors thank all the families for their participation in the LISA study. Furthermore, we thank all members of the LISA Study Group for their excellent work. The LISAplus Study group consists of the following: Helmholtz Zentrum München, German Research Center for Environmental Health, Institute of Epidemiology I, Munich (Heinrich J, Schnappinger M, Brüske I, Ferland M, Schulz H, Zeller C, Standl M, Thiering E, Tiesler C, Flexeder C); Department of Pediatrics, Municipal Hospital "St. Georg", Leipzig (Borte M, Diez U, Dorn C, Braun E); Marien Hospital Wesel, Department of Pediatrics, Wesel (von Berg A, Berdel D, Stiers G, Maas B); Pediatric Practice, Bad Honnef (Schaaf B); Helmholtz Centre of Environmental Research - UFZ, Department of Environmental Immunology/Core Facility Studies, Leipzig (Lehmann I, Bauer M, Röder S, Schilde M, Nowak M, Herberth G, Müller J); Technical University Munich, Department of Pediatrics, Munich (Hoffmann U, Paschke M, Marra S); Clinical Research Group Molecular Dermatology, Department of Dermatology and Allergy, Technische Universität München (TUM), Munich (Ollert M, J. Grosch).

\section{Authors' contributions}

JSJ analyzed the data and wrote the first draft of the report. UE and JS J developed the methodological and analytical approach. All authors revised and approved the final report

\section{Funding}

The funding agencies supporting this work are as follows: Italy: the Ministry of Agricultural, Food and Forestry Policies Ireland: The Health Research Board; The Netherlands: The Netherlands Organisation for Health Research and Development (ZonMw); and Norway: The Research Council of Norway, Division for Society and Health. The pooling of the data was funded through a grant from the National Prevention Research Initiative (Grant Number: G0701877) (http://www.mrc.ac.uk/research/initiatives/national-preventionresearch-initiative-npri/). The funding partners relevant to this award are: British Heart Foundation; Cancer Research UK; Department of Health; Diabetes UK; Economic and Social Research Council; Medical Research Council; Research and Development Office for the Northern Ireland Health and Social Services; Chief Scientist Office; Scottish Executive Health Department; The Stroke Association; Welsh Assembly Government and World Cancer Research Fund. This work was additionally supported by the Medical Research Council [MC_UU_12015/3; MC_UU_12015/7], The Research Council of Norway (249932/F20), Bristol University, Loughborough University and Norwegian School of Sport Sciences.

\section{Availability of data and materials}

The datasets during and/or analyzed during the current study are available from the corresponding author on reasonable request.

\section{Ethics approval and consent to participate}

Local ethics committee approval, parental/legal guardian consent, and child assent were obtained in all studies. Consent to participate outlined in the main methods section.

\section{Consent for publication}

Not applicable.

\section{Competing interests}

The authors declare that they have no competing interests.

\section{Author details}

${ }^{1}$ Department of Sports Medicine, Norwegian School of Sport Sciences, PO Box 4014, Ullevål Stadion, 0806 Oslo, Norway. ${ }^{2}$ Population Health Sciences, Bristol Medical School, Bristol, UK. ${ }^{3}$ Research Unit for Exercise Epidemiology and Centre of Research in Childhood Health, Department of Sports Science and Clinical Biomechanics, University of Southern Denmark, Odense, Denmark. ${ }^{4}$ Epidemiology, Biostatistcs and Prevention Institute, University Zürich, Zürich, Switzerland. ${ }^{5}$ Centre for Exercise, Nutrition and Health Sciences, University of Bristol, Bristol, UK. ${ }^{6}$ Obstetric service, Lausanne University Hospital, Lausanne, Switzerland. 'Physical Activity for Health Group, School of Psychological Sciences and Health, University of Strathclyde, Glasgow, Scotland. ${ }^{8}$ Portugal, Exercise and Health Laboratory, Faculty of Human Kinetics, Universidade de Lisboa, Lisbon, Portugal. ${ }^{9}$ Centre for Diet and Activity Research (CEDAR) \& MRC Epidemiology Unit, University of Cambridge, Cambridge, UK. ${ }^{10}$ Department of Sport, Food and Natural Sciences, Faculty of Education, Arts and Sports, Western Norway University of Applied Sciences, Sogndal, Norway. ${ }^{11}$ Department of Public and Occupational Health, Amsterdam Public Health Research Institute, VU University Medical Center, Amsterdam, Netherlands. ${ }^{12}$ Leibniz Institute for Prevention Research and Epidemiology - BIPS, Bremen, Germany.

${ }^{13}$ Helmholtz Zentrum München, German Research Center for Environmental Health, Institute of Epidemiology, Neuherberg, Germany. ${ }^{14}$ GENUD research group, Facultad de Ciencias de la Salud, Universidad de Zaragoza, Insituto Agroalimentario de Aragón (IA2), Instituto de Investigación Sanitaria Aragón (IIS Aragón), Centro de Investigación Biomédica en Red Fisiopatología de la Obesidad y Nutrición (CIBEROBN), Zaragoza, Spain. ${ }^{15}$ Department of Public Health and Primary Care, Faculty of Medicine and Health Sciences, Ghent University, Ghent, Belgium. ${ }^{16}$ School of Sport Sciences, University of Granada, Granada, Spain. ${ }^{17}$ PAFS Research group, Faculty of Sports Sciences, UCLM, Ciudad Real, Spain. ${ }^{18}$ Department of Food and Nutrition, University of Helsinki, Helsinki, Finland. ${ }^{19}$ Institute for Physical Education and Sport, University of Malta, Msida, Malta. ${ }^{20}$ Department of Nutrition, Exercise and Sports Unit for obesity research Faculty of Science, University of Copenhagen, Copenhagen, Denmark. ${ }^{21}$ Faculty of Sport, University of Porto, Porto, Portugal. ${ }^{22}$ Department of Sport Science, High School of Education, Polytechnic Institute of Porto, Porto, Portugal. ${ }^{23}$ Institute of Health \& Society and Human Nutrition Research Centre, Newcastle University, Newcastle upon Tyne, UK. ${ }^{24}$ Population Health Research Institute, St George's, University of London, London, UK. ${ }^{25}$ Department of Biomedicine and Public Health, School of Health and Education, University of Skövde, Skövde, Sweden. ${ }^{26}$ CREA Research Centre for Food and Nutrition, Rome, Italy. ${ }^{27}$ National Research Council, Institute of Food Sciences, Avellino, Italy. ${ }^{28}$ Inserm, CHU Lille,U995 - LIRIC - Lille Inflammation Research International Center, CIC 1403 - Clinical Investigation Centre, University of Lille, F-59000 Lille, France.

${ }^{29}$ Research and Education Institute of Child Health, Strovolos, Cyprus.

${ }^{30}$ National Institute for Health Development, Tervise Arengu Instituut, Tallin, Estonia. ${ }^{31}$ University of Pecs, Medical Faculty, Pécs, Hungary. ${ }^{32}$ Department of Nutrition \& Dietetics, Harokopio University, Athens, Greece. ${ }^{33}$ Department of Psychology, Estonian Centre of Behavioural and Health Sciences, University of Tartu, Tartu, Estonia. ${ }^{34}$ School of Medicine, University of Crete, Heraklion, Greece.

Received: 2 September 2019 Accepted: 12 February 2020 Published online: 18 March 2020

\section{References}

1. Janssen I, Leblanc AG. Systematic review of the health benefits of physical activity and fitness in school-aged children and youth. Int J Behav Nutr Phys Act. 2010;7:40. 
2. Poitras VJ, Gray CE, Borghese MM, Carson V, Chaput JP, Janssen I, Katzmarzyk PT, Pate RR, Connor Gorber S, Kho ME, et al. Systematic review of the relationships between objectively measured physical activity and health indicators in school-aged children and youth. Appl Physiol Nutr Metab. 2016;41(6 Suppl 3):S197-239.

3. Ekelund U, Luan J, Sherar LB, Esliger DW, Griew P, Cooper A. Moderate to vigorous physical activity and sedentary time and cardiometabolic risk factors in children and adolescents. Jama. 2012;307(7):704-12.

4. Cooper AR, Goodman A, Page AS, Sherar LB, Esliger DW, van Sluijs EM, Andersen LB, Anderssen S, Cardon G, Davey R, et al. Objectively measured physical activity and sedentary time in youth: the International children's accelerometry database (ICAD). Int J Behav Nutr Phys Act. 2015;12:113.

5. Van Hecke L, Loyen A, Verloigne M, van der Ploeg HP, Lakerveld J, Brug J, De Bourdeaudhuij I, Ekelund U, Donnelly A, Hendriksen I, et al. Variation in population levels of physical activity in European children and adolescents according to cross-European studies: a systematic literature review within DEDIPAC. Int J Behav Nutr Phys Act. 2016;13:70.

6. Guinhouya BC, Samouda H, de Beaufort C. Level of physical activity among children and adolescents in Europe: a review of physical activity assessed objectively by accelerometry. Public Health. 2013;127(4):301-11.

7. Ruiz JR, Ortega FB, Martinez-Gomez D, Labayen I, Moreno LA, De Bourdeaudhuij I, Manios Y, Gonzalez-Gross M, Mauro B, Molnar D, et al. Objectively measured physical activity and sedentary time in European adolescents: the HELENA study. Am J Epidemiol. 2011;174(2):173-84.

8. Konstabel K, Veidebaum T, Verbestel V, Moreno LA, Bammann K, Tornaritis M, Eiben G, Molnar D, Siani A, Sprengeler O, et al. Objectively measured physical activity in European children: the IDEFICS study. Int J Obes (2005). 2014;38(Suppl 2):S135-43.

9. Sherar LB, Griew P, Esliger DW, Cooper AR, Ekelund U, Judge K, Riddoch C. International children's accelerometry database (ICAD): design and methods. BMC Public Health. 2011;11:485.

10. Evenson KR, Catellier DJ, Gill K, Ondrak KS, McMurray RG. Calibration of two objective measures of physical activity for children. J Sports Sci. 2008;26(14):1557-65.

11. Trost SG, Loprinzi PD, Moore R, Pfeiffer KA. Comparison of accelerometer cut points for predicting activity intensity in youth. Med Sci Sports Exerc. 2011;43(7):1360-8.

12. Migueles JH, Cadenas-Sanchez C, Ekelund U, Delisle Nystrom C, MoraGonzalez J, Lof M, Labayen I, Ruiz JR, Ortega FB. Accelerometer Data Collection and Processing Criteria to Assess Physical Activity and Other Outcomes: A Systematic Review and Practical Considerations. Sports Med (Auckland, NZ). 2017;47(9):1821-45.

13. Cole TJ, Flegal KM, Nicholls D, Jackson AA. Body mass index cut offs to define thinness in children and adolescents: international survey. BMJ (Clinical research ed). 2007;335(7612):194.

14. Golding J, Pembrey M, Jones R. ALSPAC--the Avon longitudinal study of parents and children. I. Study methodology. Paediatr Perinat Epidemiol. 2001;15(1):74-87.

15. Niederer I, Kriemler S, Zahner L, Burgi F, Ebenegger V, Hartmann T, Meyer U, Schindler C, Nydegger A, Marques-Vidal P, et al. Influence of a lifestyle intervention in preschool children on physiological and psychological parameters (Ballabeina): study design of a cluster randomized controlled trial. BMC Public Health. 2009;9:94.

16. Cardon G, Labarque V, Smits D, De Bourdeaudhuij I. Promoting physical activity at the pre-school playground: the effects of providing markings and play equipment. Prev Med. 2009:48(4):335-40.

17. Eiberg S, Hasselstrom H, Gronfeldt V, Froberg K, Svensson J, Andersen LB. Maximum oxygen uptake and objectively measured physical activity in Danish children 6-7 years of age: the Copenhagen school child intervention study. Br J Sports Med. 2005;39(10):725-30.

18. Riddoch C, Edwards D, Page A, Froberg K, Anderssen SA, Wedderkopp N, Brage S, Cooper AR, Sardinha LB, Harro M. The European youth heart study - cardiovascular disease risk factors in children: rationale, aims, study design, and validation of methods. J Phys Act Health. 2005;2(1):115-29.

19. Zahner L, Puder JJ, Roth R, Schmid M, Guldimann R, Puhse U, Knopfli M, Braun-Fahrlander C, Marti B, Kriemler S. A school-based physical activity program to improve health and fitness in children aged 6-13 years ("kinderSportstudie KISS"): study design of a randomized controlled trial [ISRCTN15360785]. BMC Public Health. 2006;6:147.

20. Page AS, Cooper AR, Griew P, Davis L, Hillsdon M. Independent mobility in relation to weekday and weekend physical activity in children aged 10-11 years: the PEACH project. Int J Behav Nutr Phys Act. 2009;6:2.
21. van Sluijs EM, Skidmore PM, Mwanza K, Jones AP, Callaghan AM, Ekelund U, Harrison F, Harvey I, Panter J, Wareham NJ, et al. Physical activity and dietary behaviour in a population-based sample of British 10-year old children: the SPEEDY study (sport, physical activity and eating behaviour: environmental determinants in young people). BMC Public Health. 2008;8:388.

22. Kolle E, Steene-Johannessen J, Andersen LB, Anderssen SA. Objectively assessed physical activity and aerobic fitness in a population-based sample of Norwegian 9- and 15-year-olds. Scand J Med Sci Sports. 2010;20(1):e41-7.

23. Moreno LA, De Henauw S, Gonzalez-Gross M, Kersting M, Molnar D, Gottrand F, Barrios L, Sjostrom M, Manios Y, Gilbert CC, et al. Design and implementation of the Healthy Lifestyle in Europe by Nutrition in Adolescence Cross-Sectional Study. Int J Obes (2005). 2008;32(Suppl 5):S411.

24. Ahrens W, Bammann K, Siani A, Buchecker K, De Henauw S, lacoviello L, Hebestreit A, Krogh V, Lissner L, Mårild S. The IDEFICS cohort: design, characteristics and participation in the baseline survey. Int J Obes. 2011;35: S3-S15.

25. Basterfield L, Adamson AJ, Frary JK, Parkinson KN, Pearce MS, Reilly JJ. Longitudinal study of physical activity and sedentary behavior in children. Pediatrics. 2011;127(1):e24-30.

26. Toftager M, Christiansen LB, Ersboll AK, Kristensen PL, Due P, Troelsen J. Intervention effects on adolescent physical activity in the multicomponent SPACE study: a cluster randomized controlled trial. PLoS One. 2014;9(6): e99369.

27. Hjorth MF, Chaput JP, Ritz C, Dalskov SM, Andersen R, Astrup A, Tetens I, Michaelsen KF, Sjodin A. Fatness predicts decreased physical activity and increased sedentary time, but not vice versa: support from a longitudinal study in 8- to 11-year-old children. Int J Obes (2005). 2014;38(7):959-65.

28. De Meester F, De Bourdeaudhuij I, Deforche B, Ottevaere C, Cardon G. Measuring physical activity using accelerometry in 13-15-year-old adolescents: the importance of including non-wear activities. Public Health Nutr. 2011;14(12):2124-33.

29. Marques A, Santos R, Ekelund U, Sardinha LB. Association between physical activity, sedentary time, and healthy fitness in youth. Med Sci Sports Exerc. 2015;47(3):575-80.

30. Decelis A, Jago R, Fox KR. Physical activity, screen time and obesity status in a nationally representative sample of Maltese youth with international comparisons. BMC Public Health. 2014;14:664.

31. Laguna M, Ruiz JR, Lara MT, Aznar S. Recommended levels of physical activity to avoid adiposity in Spanish children. Pediatr Obes. 2013;8(1):62-9.

32. Olesen LG, Kristensen PL, Korsholm L, Froberg K. Physical activity in children attending preschools. Pediatrics. 2013;132(5):e1310-8.

33. Vale S, Ricardo N, Soares-Miranda L, Santos R, Moreira C, Mota J. Parental education and physical activity in pre-school children. Child Care Health Dev. 2014;40(3):446-52.

34. Owen CG, Nightingale CM, Rudnicka AR, Cook DG, Ekelund U, Whincup PH. Ethnic and gender differences in physical activity levels among 9-10-yearold children of white European, south Asian and African-Caribbean origin: the child heart health study in England (CHASE study). Int J Epidemiol. 2009; 38(4):1082-93.

35. Katzmarzyk PT, Barreira TV, Broyles ST, Champagne CM, Chaput JP, Fogelholm M, Hu G, Johnson WD, Kuriyan R, Kurpad A, et al. Physical activity, sedentary time, and obesity in an international sample of children. Med Sci Sports Exerc. 2015;47(10):2062-9.

36. Smith MP, Berdel D, Nowak D, Heinrich J, Schulz H. Physical activity levels and domains assessed by Accelerometry in German adolescents from GINIplus and LISAplus. PLoS One. 2016;11(3):e0152217.

37. Reilly JJ, Kelly L, Montgomery C, Williamson A, Fisher A, McColl JH, Lo Conte R, Paton JY, Grant S. Physical activity to prevent obesity in young children: cluster randomised controlled trial. BMJ (Clinical research ed). 2006; 333(7577):1041.

38. Aibar A, Bois JE, Generelo E, Zaragoza Casterad J, Paillard T. A cross-cultural study of adolescents' physical activity levels in France and Spain. Eur J Sport Sci. 2013;13(5):551-8.

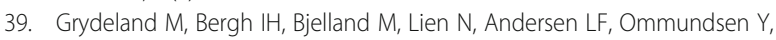
Klepp Kl, Anderssen SA. Intervention effects on physical activity: the HEIA study - a cluster randomized controlled trial. Int J Behav Nutr Phys Act. 2013;10:17.

40. Jago R, Davison KK, Brockman R, Page AS, Thompson JL, Fox KR. Parenting styles, parenting practices, and physical activity in 10- to 11-year olds. Prev Med. 2011;52(1):44-7. 
41. Wedderkopp N, Jespersen E, Franz C, Klakk H, Heidemann M, Christiansen C, Moller NC, Leboeuf-Yde C. Study protocol. The Childhood Health, Activity, and Motor Performance School Study Denmark (The CHAMPS-study DK). BMC Pediatr. 2012;12:128.

42. Kipping RR, Howe LD, Jago R, Campbell R, Wells S, Chittleborough CR, Mytton J, Noble SM, Peters TJ, Lawlor DA. Effect of intervention aimed at increasing physical activity, reducing sedentary behaviour, and increasing fruit and vegetable consumption in children: active for Life Year 5 (AFLY5) school based cluster randomised controlled trial. BMJ (Clinical research ed). 2014;348:g3256.

43. Audrey S, Bell S, Hughes R, Campbell R. Adolescent perspectives on wearing accelerometers to measure physical activity in population-based trials. Eur J Pub Health. 2013;23(3):475-80.

44. Griffiths LJ, Sera F, Cortina-Borja M, Law C, Ness A, Dezateux C. Objectively measured physical activity and sedentary time: cross-sectional and prospective associations with adiposity in the millennium cohort study. BMJ Open. 2016;6(4):e010366.

45. Coombs N, Shelton N, Rowlands A, Stamatakis E. Children's and adolescents' sedentary behaviour in relation to socioeconomic position. J Epidemiol Community Health. 2013;67(10):868-74.

46. Marques EA, Pizarro Al, Mota J, Santos MP. Independent mobility and its relationship with moderate-to-vigorous physical activity in middle-school Portuguese boys and girls. J Phys Act Health. 2014; 11(8):1640-3

47. Nilsson A, Anderssen SA, Andersen LB, Froberg K, Riddoch C, Sardinha LB, Ekelund $U$. Between- and within-day variability in physical activity and inactivity in 9- and 15-year-old European children. Scand J Med Sci Sports. 2009;19(1):10-8.

48. Gomes TN, Katzmarzyk PT, Hedeker D, Fogelholm M, Standage M, Onywera V, Lambert EV, Tremblay MS, Chaput JP, Tudor-Locke C, et al. Correlates of compliance with recommended levels of physical activity in children. Sci Rep. 2017;7(1):16507.

49. Dumith SC, Gigante DP, Domingues MR, Kohl HW 3rd. Physical activity change during adolescence: a systematic review and a pooled analysis. Int J Epidemiol. 2011;40(3):685-98.

50. Farooq MA, Parkinson KN, Adamson AJ, Pearce MS, Reilly JK, Hughes AR, Janssen X, Basterfield L, Reilly JJ. Timing of the decline in physical activity in childhood and adolescence: Gateshead millennium cohort study. Br J Sports Med. 2018;52(15):1002-6.

51. Wijnhoven TM, van Raaij JM, Spinelli A, Rito Al, Hovengen R, Kunesova M, Starc G, Rutter H, Sjoberg A, Petrauskiene A, et al. WHO European childhood obesity surveillance initiative 2008: weight, height and body mass index in 6-9-year-old children. Pediatr Obes. 2013;8(2):79-97.

52. Costa S, Barber SE, Cameron N, Clemes SA. Calibration and validation of the ActiGraph GT3X+ in 2-3 year olds. J Sci Med Sport. 2014;17(6): 617-22.

53. Pate RR, Almeida MJ, Mclver KL, Pfeiffer KA, Dowda M. Validation and calibration of an accelerometer in preschool children. Obesity (Silver Spring). 2006;14(11):2000-6.

54. Robusto KM, Trost SG. Comparison of three generations of ActiGraph activity monitors in children and adolescents. J Sports Sci. 2012;30(13):142935.

55. Corder K, Brage S, Ramachandran A, Snehalatha C, Wareham N, Ekelund U. Comparison of two Actigraph models for assessing free-living physical activity in Indian adolescents. J Sports Sci. 2007;25(14):1607-11.

56. Tarp J, Andersen LB, Ostergaard L. Quantification of underestimation of physical activity during cycling to school when using Accelerometry. J Phys Act Health. 2015;12(5):701-7.

57. Chan CB, Ryan DA. Assessing the effects of weather conditions on physical activity participation using objective measures. Int J Environ Res Public Health. 2009;6(10):2639-54

58. Hjorth MF, Chaput JP, Michaelsen K, Astrup A, Tetens I, Sjodin A. Seasonal variation in objectively measured physical activity, sedentary time, cardiorespiratory fitness and sleep duration among 8-11 year-old Danish children: a repeated-measures study. BMC Public Health. 2013;13:808.

59. Kolle E, Steene-Johannessen J, Andersen LB, Anderssen SA. Seasonal variation in objectively assessed physical activity among children and adolescents in Norway: a cross-sectional study. Int J Behav Nutr Phys Act. 2009;6:36.

60. Dalene KE, Anderssen SA, Andersen LB, Steene-Johannessen J, Ekelund U, Hansen BH, Kolle E. Secular and longitudinal physical activity changes in population-based samples of children and adolescents. Scand J Med Sci Sports. 2018;28(1):161-71.

61. Moller NC, Kristensen PL, Wedderkopp N, Andersen LB, Froberg K. Objectively measured habitual physical activity in 1997/1998 vs 2003/2004 in Danish children: the European youth heart study. Scand J Med Sci Sports. 2009;19(1):19-29.

\section{Publisher's Note}

Springer Nature remains neutral with regard to jurisdictional claims in published maps and institutional affiliations.

\section{Ready to submit your research? Choose BMC and benefit from:}

- fast, convenient online submission

- thorough peer review by experienced researchers in your field

- rapid publication on acceptance

- support for research data, including large and complex data types

- gold Open Access which fosters wider collaboration and increased citations

- maximum visibility for your research: over $100 \mathrm{M}$ website views per year

At BMC, research is always in progress.

Learn more biomedcentral.com/submissions 